\title{
BMJ Open Type 2 diabetes in Scottish military veterans: a retrospective cohort study
}

\author{
Beverly P Bergman (D , Daniel Mackay, J P Pell
}

To cite: Bergman BP, Mackay D, Pell JP. Type 2 diabetes in Scottish military veterans: a retrospective cohort study. BMJ Open 2022;12:e057431. doi:10.1136/ bmjopen-2021-057431

- Prepublication history for this paper is available online. To view these files, please visit the journal online (http://dx.doi. org/10.1136/bmjopen-2021057431).

Received 15 September 2021 Accepted 05 January 2022

Check for updates

(c) Author(s) (or their employer(s)) 2022. Re-use permitted under CC BY-NC. No commercial re-use. See rights and permissions. Published by BMJ.

Institute of Health and Wellbeing, University of Glasgow, Glasgow, UK

Correspondence to Dr Beverly P Bergman; Beverly.Bergman@glasgow. ac.uk

\begin{abstract}
Objectives Type 2 diabetes is an important public health problem but the risk in UK military veterans is unknown. We used data from the Trends in Scottish Veterans' Health study to investigate the risk in comparison with people with no record of service.

Design Retrospective cohort study of a large national sample in Scotland, with up to 37 years follow-up.

Setting Pseudoanonymised extract of computerised Scottish National Health Service records, including a disease register and national vital records.

Participants 78000 veterans and 253000 people with no record of service matched for age, sex and area of residence.
\end{abstract}

Outcome measures Cox proportional HRs for first record of type 2 diabetes in veterans compared with nonveterans, overall and by sex and birth cohort. Long-term trend, comorbidity with specific mental health outcomes and risk of limb loss.

Results Overall, $7.2 \%$ of veterans were diagnosed with type 2 diabetes, and were at slightly increased risk compared with non-veterans, Cox proportional HR 1.08, $95 \% \mathrm{Cls} 1.04$ to $1.11, \mathrm{p}<0.001$. The increased risk was confined to men, and to veterans born prior to 1960 . There has been no change in HR over the last 25 years. Among veterans with post-traumatic stress disorder (PTSD), 12.1\% had been diagnosed with type 2 diabetes, compared with $9.4 \%$ of non-veterans with PTSD. The difference was statistically significant, OR $1.29,95 \% \mathrm{Cl}$ 1.04 to $1.59, p=0.021$. Risk of limb loss was increased among the oldest veterans.

Conclusions Older veterans in Scotland have an increased risk of type 2 diabetes in comparison with nonveterans, but there is no difference in respect of younger veterans, and the pattern of risk shows no evidence that it is changing. There is a positive association between type 2 diabetes and PTSD, especially in the presence of comorbid mood disorder, an important finding which should be noted by care providers.

\section{INTRODUCTION}

Type 2 diabetes represents a major public health challenge, with numbers having doubled in 30 years, particularly in highincome countries. ${ }^{1}$ Known risk factors include obesity, ethnicity and genetics. ${ }^{23}$ It is far from a benign condition; major cardiovascular associations include ischaemic heart disease and lower limb ischaemia, and there is an increased risk of lower limb amputation. ${ }^{4}$
Strengths and limitations of this study

- This is a large retrospective study comparing longterm outcomes in veterans in Scotland with matched non-veterans.

- The health outcome data were derived from computerised National Health Service and national vital records, including a national disease register, thus reducing the risk of recall bias.

- Primary care data were not available, therefore, the results for mental health comorbidities represent only the more severe end of the spectrum where hospitalisation occurred.

- No information was available on personal lifestyle factors such as obesity which could have influenced risk of diabetes, nor on occupational factors other than a history of military service.

Thus in the long term, type 2 diabetes is an important determinant of care and welfare needs. $^{5}$

In Scotland around $5.6 \%$ of the population is living with diabetes, of which $87.9 \%$ is type 2. Age-specific prevalence of type 2 diabetes rises from $2.4 \%$ at age $40-44$ years, to $15.2 \%$ at age $70-74$ years. Among people with type 2 diabetes who have a recorded BMI, $87 \%$ are overweight or obese. ${ }^{6}$ The prevalence has been rising in recent years, although UK primary care evidence from the Clinical Practice Research Datalink suggests that there has been little change in the incidence. ${ }^{7}$ However, there is a paucity of information on the epidemiology of diabetes in the veteran population. While pre-existing diabetes is a bar to military recruitment, and leads to restriction of duties (medical downgrading) or retirement (medical discharge) if developed during service, type 2 diabetes in particular may be compatible with continued service in a reduced medical employability category, ${ }^{8}$ or it may develop after discharge from the Armed Forces.

The Armed Forces Covenant ${ }^{9}$ stipulates that members of the Armed Forces community, including veterans, should face 'no disadvantage' compared with other members of the community, and it is, therefore, important 
for healthcare providers to be aware of health conditions which may be more prevalent in those who have served. In order to address this knowledge gap in respect of type 2 diabetes, we used data from Trends in Scottish Veterans' Health, the follow-up to the 2012 Scottish Veterans Health Study, to examine the risk of the condition in Scottish veterans in comparison with age-matched, sex-matched and geographically matched non-veterans.

\section{METHODS}

Trends in Scottish Veterans' Health is a retrospective cohort study of all 78385 military veterans resident in Scotland who were born between 1 January 1945 and 31 December 1995, and a comparison group of 252637 individuals with no record of service ('non-veterans') matched 3:1 for age, sex and postcode sector of residence (mean population 5000). A full cohort description has been published elsewhere. ${ }^{10}$ Veterans were eligible for inclusion if they were registered with National Health Service (NHS) Scotland both preservice and postservice. The study updates and builds on the Scottish Veterans Health Study, using similar methodology which is fully described elsewhere. ${ }^{11}$ Demographic data obtained from electronic NHS registration records were linked at an individual level to routine hospital admissions data (Scottish Morbidity Record SMR01), psychiatric hospital admissions (SMR04), the Scottish Diabetes Register and death certificates to provide information on all first recorded diagnoses of diabetes by type, cardiovascular disease (CVD) including peripheral arterial disease $(\mathrm{PAD})$, mental health diagnoses, lower limb amputation and all-cause death. Dates of entering and leaving the Service, for veterans, were obtained from the Scottish NHS registration record. The maximum period of follow-up was from 1 January 1981 (or date of leaving the Armed Forces, for veterans, if later) to 31 December 2017 , the point at which the dataset was extracted.

\section{Patient and public involvement}

As this was a pseudoanonymised secondary data study, there was no direct patient or public involvement.

\section{Socioeconomic status}

A measure of area-based socioeconomic status (SES) is provided by the Scottish Index of Multiple Deprivation (SIMD), which subdivides the nation into 6505 datazones, defined by postcode, each covering a mean population of 800. Deprivation is assessed based on information on income, employment, health, education (including skills and training), housing, crime and access to services. From the SIMD, quintiles of SES for the Scottish population have been derived; ranging from 1 (most deprived) to 5 (least deprived). ${ }^{12}$ The cohort participants were categorised according to these general population quintiles using their postcode of residence.

\section{Statistical methods}

For the purposes of the study, a diagnosis of diabetes was defined as International Classification of Diseases
(ICD) version 10 (ICD-10) E10-E14 or ICD-9 250 at any position in the SMR record, or an entry in the Scottish Diabetes Register. For Scottish Diabetes Register entries, we restricted the analysis to type 2 diabetes. For SMR01 records, where type of diabetes was not specified in our dataset, we restricted the analysis to cases first diagnosed at age 30 or later to exclude likely cases of type 1 disease. PAD was defined as ICD-10 I73-I79 or I702 or ICD-9 443.9 or 440.2 , while CVD was defined as a composite of acute myocardial infarction (ICD-10 code I21 or ICD-9 code 410), stroke (ICD-10 codes I60-I64 or ICD-9 codes 430-432) and PAD.$^{10}$ Lower limb amputation was defined as any occurrence of OPCS-4 code X01, X07, X08, X081, $\mathrm{X} 09$, X095, X11 or X12, including subcodes where appropriate, or OPCS-3 codes $870-875$ or $862-864 .{ }^{4}$ Alcoholrelated death was defined in accordance with the National Statistics classification. ${ }^{13}$

Cox proportional hazard models were used to examine the association between veteran status and cumulative risk of type 2 diabetes, using age as the time dependent variable, age at first record of diabetes as the failure time, and death (if no diabetes) as the censor time. We also examined comorbidity with CVD, with lower limb amputation, and with mental health diagnoses overall (anxiety, mood disorders and psychosis) where this was recorded on the in-patient or death record. We specifically examined association with severe stress or posttraumatic stress disorder (PTSD) (ICD-10 F43 or ICD-9 308 or 309), and with major causes of death. HRs and $\mathrm{p}$ values were calculated and the a priori rejection level was set at 0.05 . Proportionality was tested using methodology based on Schoenfeld residuals, ${ }^{14}$ and interactions were tested using the likelihood ratio test. The models were run univariably and then repeated adjusting for the potential confounding effect of SES. The analyses were repeated stratifying by grouped year of birth in 5-year bands to examine birth cohort effects, and by length of service in categories representing most common terms of engagement. Comorbidities were examined using ORs. All analyses were performed using Stata V.16.

\section{RESULTS}

After data cleansing to remove 228 veterans with invalid dates of service, $78157(99.7 \%)$ were included in the analysis, together with 252637 people with no record of military service. No non-veterans were excluded as a result of data cleansing. There were 7573 women among the veterans $(9.7 \%)$, reflecting the gender balance of the Armed Forces.

Over up to 37 years of follow-up, there were 5663 $(7.2 \%)$ incident cases of type 2 diabetes among the veterans, compared with $16175(6.4 \%)$ in non-veterans. Overall, veterans were at slightly increased risk, Cox proportional HR 1.08, 95\% CI 1.04 to $1.11, \mathrm{p}<0.001$, although the increase was confined to older veterans as shown in the Nelson-Aalen plot (figure 1). The likelihood ratio test for interaction was highly significant, $\mathrm{p}<0.001$. 


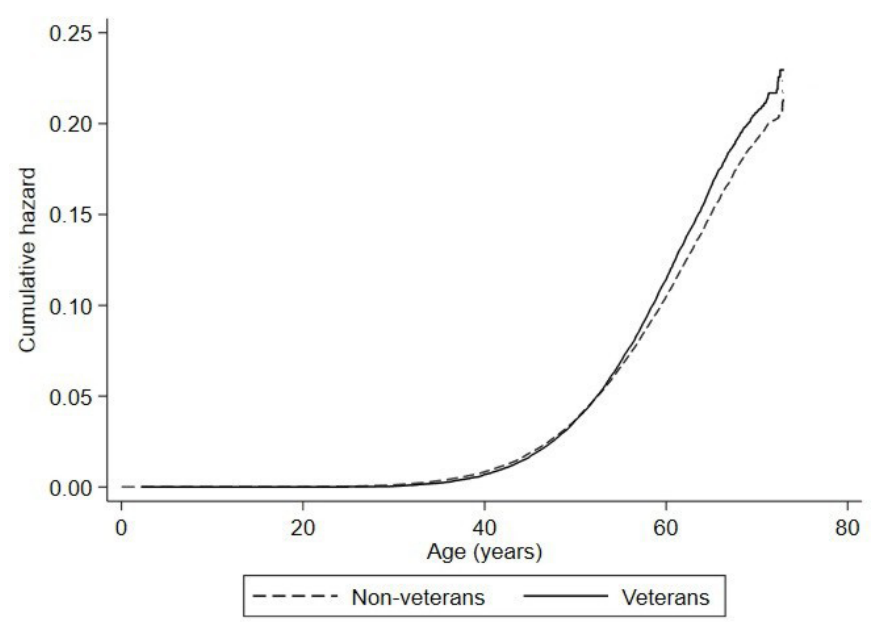

Figure 1 Nelson-Aalen plot of risk of type 2 diabetes in veterans and non-veterans.

Adjusting for SES resulted in only a slight attenuation of overall risk, HR 1.06, 95\% CI 1.02 to 1.09 . p $<0.001$. The increase in risk was confined to male veterans. There were $5377(7.6 \%)$ cases in male veterans, compared with $15031(6.7 \%)$ cases in male non-veterans, HR 1.07, 95\% CI 1.04 to $1.10, \mathrm{p}<0.001$, while the corresponding figures for women were $286(3.8 \%)$ for veterans and 1144 (4.0\%) for non-veterans, HR 1.00, 95\% CI 0.88 to $1.14, \mathrm{p}=0.964$. The likelihood ratio test for interaction with sex was nonsignificant, $\mathrm{p}=0.312$.

Analysis by birth cohort confirmed that the excess risk was restricted to veterans born before 1965, although it only became statistically significant for veterans born prior to 1960 (figure 2). The unadjusted HR for pre-1960 births was $1.11,95 \%$ CI 1.08 to $1.16, p<0.001$, compared with $0.96,95 \%$ CI 0.91 to $1.02, p=0.235$ for people born from 1960 onwards. For the pre-1960 birth cohorts, length of veterans' service had little impact on the increased risk of type 2 diabetes, although those with over 16 years' service had no significant increase in risk compared with nonveterans. For veterans born from 1960 onwards, there was no increase in risk in any length of service group other

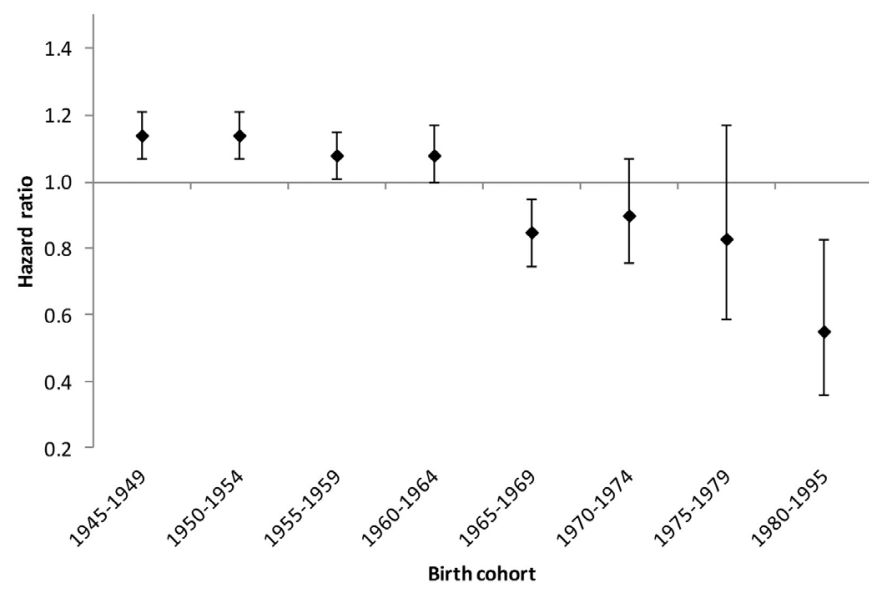

Figure 2 HRs for type 2 diabetes in veterans and nonveterans, by birth cohort.

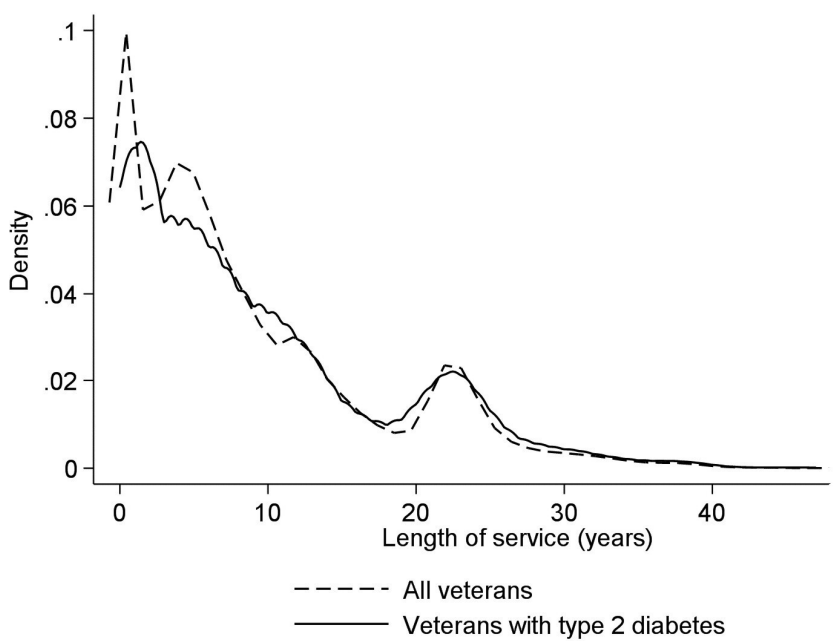

Figure 3 Kernel density graph for veterans with diabetes by length of service, compared with all veterans.

than the Early Service Leavers, although their increase was non-significant. The kernel density graph for all veterans with diabetes by length of service (figure 3 ) demonstrates that it closely matches the curve for all veterans.

By the end of follow-up, 750 (13.2\%) veterans with type 2 diabetes had died, compared with 2109 (13.0\%) nonveterans with type 2 diabetes. There was no statistically significant difference in case-fatality between veterans and non-veterans, OR 1.02, 95\% CI 0.94 to $1.10, \mathrm{p}=0.693$. The most common cause of death in both veterans and non-veterans was acute myocardial infarction or ischaemic heart disease, accounting for $24.1 \%$ of deaths in veterans with type 2 diabetes and $21.6 \%$ in non-veterans. The second most common cause of death was lung cancer. Alcohol-related causes accounted for $5.6 \%$ of the deaths in veterans with type 2 diabetes and $7.4 \%$ of deaths in diabetic non-veterans; the reduction in veterans was not statistically significant, OR $0.75,95 \%$ CI 0.54 to 1.05 , $\mathrm{p}=0.088$.

We performed a sensitivity analysis to examine trends over time, looking at the notional risk if the analysis had been performed at earlier points, and found that the increase in risk was highest in 1983, although the CIs were wide as the oldest of the study subjects was only 38 years of age and there were few cases. The excess risk in veterans fell rapidly thereafter to reach a steady pattern of either no increase, or only a small increase, since the late 1980s (figure 4). In the last 25 years, there has been no evidence of changing risk in veterans, relative to non-veterans, over time.

Veterans who had a type 2 diabetes diagnosis were no more likely to have a mental health diagnosis overall than diabetic non-veterans, OR 1.06, 95\% CI 0.96 to 1.16 , $\mathrm{p}=0.251$, but they were twice as likely as non-veterans to have been hospitalised with PTSD, OR 2.02, 95\% CI 1.61 to 2.52, $\mathrm{p}<0.001$. Among veterans with PTSD, $12.1 \%$ had been diagnosed with type 2 diabetes, compared with $9.4 \%$ of non-veterans with PTSD. The difference was statistically 


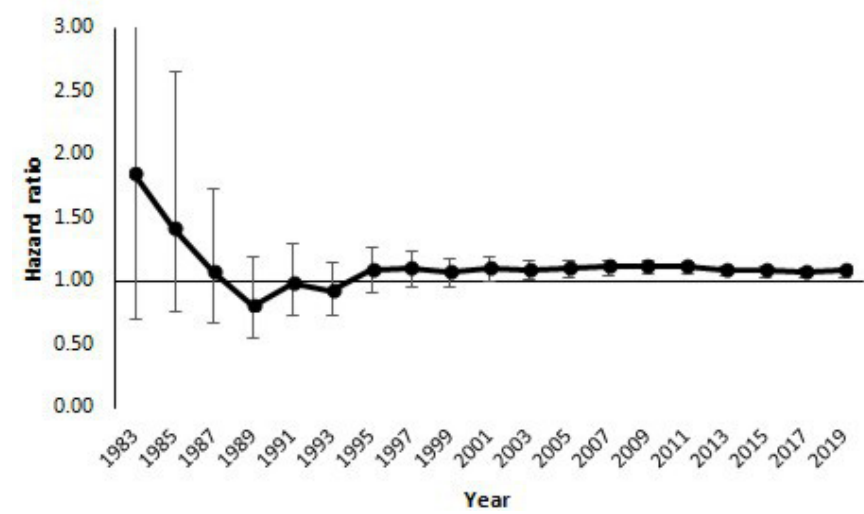

Figure 4 HRs for type 2 diabetes at notional earlier endpoints, veterans compared with non-veterans.

significant, OR $1.29,95 \%$ CI 1.04 to $1.59, \mathrm{p}=0.021$. Around half of both veterans and non-veterans with type 2 diabetes and PTSD had an associated diagnosis of mood disorder. Veterans overall were more likely to have PTSD and comorbid mood disorder compared with nonveterans, OR $1.76,95 \%$ CI 1.57 to $1.98, \mathrm{p}<0.001$ and, of those veterans, $14.4 \%$ had type 2 diabetes, compared with $12.4 \%$ of non-veterans with the dual mental health diagnosis, although the difference did not achieve statistical significance.

There was a small increase in the positive association between CVD and diabetes in veterans in comparison with non-veterans, OR $1.16,95 \%$ CI 1.09 to 1.25 , $\mathrm{p}<0.001$ for a CVD diagnosis in those with type 2 diabetes, and OR $1.10,95 \%$ CI 1.03 to $1.17, \mathrm{p}=0.005$ for a diagnosis of type 2 diabetes for those with CVD. ${ }^{10}$ Over the period of the study, 61 veterans with diabetes $(1.08 \%)$ underwent a lower limb amputation, compared with 154 (0.95\%) of non-veterans with diabetes. The difference was not statistically significant overall, HR $1.03,95 \%$ CI 0.77 to $1.41, p=0.807$, although there was an increase in risk for veterans born prior to 1955 , HR 1.12, 95\% CI 1.08 to 1.15 , $\mathrm{p}<0.001{ }^{4}$

\section{DISCUSSION}

In the first study, to our knowledge, of the long-term risk of type 2 diabetes in a UK veteran cohort in comparison with people with no record of military service, we have found a modest increase in risk in those born prior to 1960, except those with the longest military service, but no increase in risk among veterans born from 1960 onwards. Our findings also provide reassurance that the risk in comparison with non-veterans is not increasing over time. The pattern of change in risk from an excess in earlier-born veterans, to no significant difference or a reduction in risk in veterans born from 1960 onwards, mirrors the pattern seen in many conditions in our other veteran health studies, including CVD. In our recent paper on trends in CVD, ${ }^{10}$ we report that the neutral inflection point at 1960 remained unchanged between the 2012 and 2017 datasets, despite ageing of the cohort by 5 years, suggesting a genuine change in risk profile.

People who were born in 1960 and later would have generally joined the Armed Forces from 1978, when the emerging Defence Health Strategy began to be implemented with the introduction of a Basic Fitness Test and mandatory health promotion in the Army. ${ }^{15}$ We, therefore, find increasing evidence that this has had a measurable and lasting beneficial impact on the health of later veterans, excluding those who left prior to the completion of initial training and whose service was not long enough to benefit (Early Service Leavers). With the oldest of this post-1959 birth cohort aged 57 years at the end of data collection, and the risk of type 2 diabetes increasing from the mid-40s, ${ }^{16}$ it is unlikely that the observed finding is an artefact due to the cohort not yet having reached peak incidence.

Notwithstanding that the risk for veterans now is no greater than for non-veterans, diabetes is an important public health problem, ${ }^{1}$ and obesity is recognised to be a major risk factor. ${ }^{2}$ The majority of studies on obesity in the military have come from the USA, but a 2013 UK study drew on data from the British Army Fitness Information Statistical Software system and concluded that $12.0 \%$ of serving male military personnel and $8.6 \%$ of females met the BMI criteria for obesity. Those who were obese were more likely to be older and of lower rank, while combat soldiers were at lowest risk of obesity. ${ }^{17}$ The authors concluded that $24 \%$ of male and $30 \%$ of female soldiers were at increased risk of obesity-related disease, lower than the UK civilian rate of $57 \%$ of men and $56 \%$ of women. ${ }^{18}$ No studies of obesity in UK veterans overall have been identified, although $35.5 \%$ of a sample of veterans seeking help for mental health problems were found to be obese. ${ }^{19}$

An important finding from our study was the positive association between type 2 diabetes and PTSD, although the nature of our data and natural history of both conditions did not permit the direction of putative causality to be determined. Our finding mirrors that of the US military Millennium Cohort Study, which examined risk factors for developing diabetes and found that baseline PTSD was significantly associated with risk of diabetes (OR 2.07, 95\% CI 1.31 to 3.29), similar to our own finding, but that there was no association between diabetes and other mental health conditions or deployment. ${ }^{20}$ The risk increases in the presence of comorbid depression, ${ }^{21}$ which is similarly supported by our findings. Data on middle-aged men followed up in the Vietnam Era Twin Study have shown a $40 \%$ increase in prospective risk of diabetes in those with PTSD. ${ }^{22}$ Attempts have been made to model the influence of poor health behaviours in veterans to explain the association between PTSD, diabetes and CVD, although the results have been inconclusive. ${ }^{23}$ Studies in civilian populations have also demonstrated an association between PTSD and type 2 diabetes; a mechanism of chronic stress leading to a chronic inflammatory response has been postulated. ${ }^{24} \mathrm{~A}$ history of 
adverse childhood events has also been suggested as a risk factor; a review of the evidence generally found a positive association with both physical and sexual abuse in childhood and development of type 2 diabetes in adulthood. ${ }^{25}$ The association between adverse childhood events and later PTSD is well documented, including in UK military personnel. ${ }^{26}{ }^{27}$ Our finding highlights the importance of a holistic approach to veterans (and indeed to nonveterans) presenting with symptoms of PTSD, to exclude treatable comorbidities such as diabetes, encourage treatment compliance where appropriate, and ensure delivery of preventive advice.

The finding that there has been little change in the risk relative to non-veterans for nearly 30 years also provides reassurance that it is unlikely that there are other militaryspecific factors now influencing the risk of type 2 diabetes in veterans. Older veterans (pre-1960 birth cohorts), by contrast, generally demonstrate poorer long-term health than people who have never served, especially in respect of lifestyle-related morbidity such as $\mathrm{CVD}^{1011}$ and, from our present study, diabetes. It is plausible that this reflects unhealthy behaviours such as smoking, obesity and lack of exercise during and after their service at a time when healthy behaviour patterns were not actively promoted in the Armed Forces, while those who adopted a healthy lifestyle during service tended to maintain that lifestyle as a veteran. ${ }^{28}$ This has important implications for care and welfare needs in the ageing veteran population, as well as presenting opportunities for targeted health promotion for veterans in primary care.

Strengths of this study include the very large dataset and long period of follow-up. Access to data from the Scottish Diabetes Register as well as Scottish computerised secondary healthcare records has maximised case ascertainment. The use of record linkage to analyse individual level data directly derived from health records allowed a robust cohort study design to be employed, while data on sex, year of birth and length of service facilitated subgroup analysis.

Limitations include possible loss to follow-up of subjects due to migration away from Scotland, which could not be quantified so the assumption has been made that there was no systematic difference in this respect between veterans and non-veterans. No data were available on obesity at an individual level so we have cited other published studies on obesity in serving personnel. In the absence of information on lifestyle factors, it is possible that residual confounding may have been present, of which we had no visibility. Primary care data were not available, therefore, the data for mental health represent only the more severe end of the spectrum where hospitalisation resulted. We have been unable to link to in-service records, therefore any cases arising during military service will not have been captured until after leaving service and returning to NHS care, although it is unlikely that this would have affected our findings. We were not able to determine the Service (Royal Navy, Army, Royal Air Force) to which a veteran belonged, and other than a history of military service we had no data on occupational factors, so we were unable to examine the effect of these. Veterans with Reserve service only could not be identified from NHS records and were therefore included among the non-veterans; this would have had the effect of reducing any observed differences between veterans and non-veterans although the numbers involved are likely to be too small to have an important impact on our findings. The number of veterans excluded during data cleansing is also small and therefore unlikely to impact on our findings. It is estimated that around $14 \%$ of people in Scotland with type 2 diabetes have not yet been diagnosed, ${ }^{29}$ and will not, therefore, appear on NHS records. We have made the assumption that the prevalence of undiagnosed diabetes does not differ between veterans and non-veterans.

\section{CONCLUSION}

Older veterans in Scotland (born prior to 1960) have an increased risk of type 2 diabetes in comparison with people who have never served, but there is no difference in respect of younger veterans, and the pattern of risk shows no evidence that it is changing. We found an important positive association between type 2 diabetes and PTSD which was stronger in veterans than in nonveterans and was consistent with studies of US veterans. Lifestyle advice aimed at reducing the burden of diabetes in older veterans would be of benefit, but most importantly, providers of care to veterans suffering from PTSD should be aware of their increased risk of type 2 diabetes and should ensure appropriate screening, advice and, where necessary, treatment.

Acknowledgements We thank the NHS Central Registry for extracting the dataset, and the eDRIS Team (Public Health Scotland) for obtaining approvals, provisioning and linking data and the use of the secure analytical platform within the National Safe Haven.

Contributors BPB conceived the idea and designed the study, with advice from JPP and DM. BPB carried out the data analysis, which was overseen by DM, and interpreted the findings. BPB wrote the first draft of the report, which was critically reviewed and edited by all authors. BPB revised the paper following review, and all authors approved the final article. JPP is the guarantor.

Funding 'Trends in Scottish Veterans Health' is funded by a grant from the Forces in Mind Trust, grant no. FiMT17/1101UG.

Competing interests BPB is a military veteran and Honorary Civilian Consultant Advisor (Army) in Veterans' Health and Epidemiology, an unfunded position.

Patient and public involvement Patients and/or the public were not involved in the design, or conduct, or reporting, or dissemination plans of this research.

Patient consent for publication Not applicable.

Ethics approval This study involves human participants and was approved by Public Benefit and Privacy Panel, Information Services Division, NHS Scotland (Approval number 1718-0133). As a pseudoanonymised secondary data study, individual consent was not required.

Provenance and peer review Not commissioned; externally peer reviewed.

Data availability statement No data are available. The study remains in progress and data are not currently available for sharing.

Open access This is an open access article distributed in accordance with the Creative Commons Attribution Non Commercial (CC BY-NC 4.0) license, which permits others to distribute, remix, adapt, build upon this work non-commercially, and license their derivative works on different terms, provided the original work is 
properly cited, appropriate credit is given, any changes made indicated, and the use is non-commercial. See: http://creativecommons.org/licenses/by-nc/4.0/.

ORCID iD

Beverly P Bergman http://orcid.org/0000-0003-4596-3399

\section{REFERENCES}

1 Chen L, Magliano DJ, Zimmet PZ. The worldwide epidemiology of type 2 diabetes mellitus - present and future perspectives. Nat Rev Endocrinol 2012;8:228-36.

2 Haffner SM. Epidemiology of type 2 diabetes: risk factors. Diabetes Care 1998;21 Suppl 3:C3-6.

3 Meigs JB, Shrader P, Sullivan LM, et al. Genotype score in addition to common risk factors for prediction of type 2 diabetes. $N$ Engl $\mathrm{J}$ Med 2008;359:2208-19.

4 Bergman BP, Mackay DF, Pell JP. Postservice lower limb amputation in Scottish military veterans. BMJ Mil Health 2021. doi:10.1136/ bmjmilitary-2020-001720. [Epub ahead of print: 25 Jan 2021].

$5 \mathrm{Kim} \mathrm{TH}$, Chun KH, Kim HJ, et al. Direct medical costs for patients with type 2 diabetes and related complications: a prospective cohort study based on the Korean national diabetes program. J Korean Med Sci 2012;27:876-82.

6 Scottish Diabetes Data Group. Scottish diabetes survey 2018. NHS Scotland, 2019.

7 Zghebi SS, Steinke DT, Carr MJ, et al. Examining trends in type 2 diabetes incidence, prevalence and mortality in the UK between 2004 and 2014. Diabetes Obes Metab 2017;19:1537-45.

8 In:Ministry of Defence. JSP346: PULHHEEMS - A Joint Service System of Medical Classification. London: Ministry of Defence, 2006Depatment SGs, editor.

9 Ministry of Defence. The armed forces covenant. London: Ministry of Defence, 2011.

10 Bergman BP, Mackay DF, Pell JP. Trends in cardiovascular disease in Scottish military veterans: a retrospective cohort study. BMJ Open 2021;11:e044465.

11 Bergman BP, Mackay DF, Pell JP. Acute myocardial infarction in Scottish military veterans: a retrospective cohort study of 57,000 veterans and 173,000 matched nonveterans. Am J Epidemiol 2014;179:1434-41.

12 Scottish Government. Scottish index of multiple deprivation 2012. Edinburgh: Scottish Government, 2012: p. 121.

13 Office for National Statistics. Alcohol-Related deaths in the United Kingdom, registered in 2012. London: National Statistics, 2014: p. 26.
14 Grambsch PM, Therneau TM. Proportional hazards tests and diagnostics based on weighted residuals. Biometrika 1994;81:515-26.

15 Ministry of Defence. Fit to fight. London: Ministry of Defence, 1978.

16 Koopman RJ, Mainous AG, Diaz VA, et al. Changes in age at diagnosis of type 2 diabetes mellitus in the United States, 1988 to 2000. Ann Fam Med 2005:3:60-3.

17 Sanderson PW, Clemes SA, Biddle SJH. Prevalence and sociodemographic correlates of obesity in the British Army. Ann Hum Biol 2014;41:193-200.

18 Health and Social Care Information Centre. Health survey for England 2012. Leeds London: Health and Social Care Information Centre, 2013.

19 Williamson V, Rossetto A, Murphy D. Relationship between obesity and health problems in help-seeking military veterans. BMJ Mil Health 2020;166:227-31.

20 Boyko EJ, Jacobson IG, Smith B, et al. Risk of diabetes in U.S. military service members in relation to combat deployment and mental health. Diabetes Care 2010;33:1771-7.

21 Trief PM, Ouimette P, Wade M, et al. Post-traumatic stress disorder and diabetes: co-morbidity and outcomes in a male veterans sample. $J$ Behav Med 2006;29:411-8.

22 Vaccarino V, Goldberg J, Magruder KM, et al. Posttraumatic stress disorder and incidence of type-2 diabetes: a prospective twin study. $J$ Psychiatr Res 2014;56:158-64.

23 Hoerster KD, Campbell S, Dolan M, et al. PTSD is associated with poor health behavior and greater body mass index through depression, increasing cardiovascular disease and diabetes risk among U.S. veterans. Prev Med Rep 2019;15:100930.

24 Lukaschek K, Baumert J, Kruse J, et al. Relationship between posttraumatic stress disorder and type 2 diabetes in a populationbased cross-sectional study with 2970 participants. J Psychosom Res 2013;74:340-5.

25 Huffhines L, Noser A, Patton SR. The link between adverse childhood experiences and diabetes. Curr Diab Rep 2016;16:54.

26 Koenen KC, Moffitt TE, Poulton R, et al. Early childhood factors associated with the development of post-traumatic stress disorder: results from a longitudinal birth cohort. Psychol Med 2007;37:181-92.

27 Iversen AC, Fear NT, Simonoff E, et al. Influence of childhood adversity on health among male UK military personnel. $\mathrm{Br} \mathrm{J}$ Psychiatry 2007;191:506-11.

28 Williamson V, Harwood H, Greenberg K, et al. Impact of military service on physical health later in life: a qualitative study of geriatric UK veterans and non-veterans. BMJ Open 2019;9:e028189.

29 Diabetes UK. Diabetes care in Scotland 2015. Available: https:// www.diabetes.org.uk/in_your_area/scotland/diabetes_in_your_area scotland [Accessed 23 Dec 21]. 